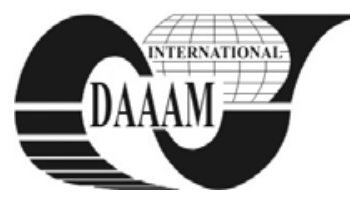

Annals of DAAAM for 2011 \& Proceedings of the 22nd International DAAAM Symposium, Volume 22, No. 1, ISSN $1726-9679$ ISBN 978-3-901509-83-4, Editor B. Katalinic, Published by DAAAM International, Vienna, Austria, EU, 2011 Make Harmony between Technology and Nature, and Your Mind will Fly Free as a Bird Annals \& Proceedings of DAAAM International 2011

\title{
MILLING OF POLYMERIC SANDWICH COMPOSITES PRODUCTS
}

\section{BIVOLARU, C[atalina] F[lorentina]; OPRAN, C[onstantin] \& MURAR, D[iana] A[nca]}

\begin{abstract}
Polymeric sandwich composites products are a great example of the potential offered by composite materials. The interest in this research and development in the area of these new materials is about the forces during this milling process. Machining of polymeric sandwich composite products was achieved against the feed and in advance the feed on a sample of size $100 \times 200 \times 23$, fiberglass faces-sheets and extruded polystyrene core with a tool which has the diameter $10 \mathrm{~mm}$. This paper deals with the analysis of the drawing graphs illustrating the influence of the parameters shown during the milling process. The result of this research on the variation of the cutting force when milling are being presented in this paper.
\end{abstract}

Key words: polymeric sandwich composite, milling process, machining

\section{INTRODUCTION}

The categories of materials made of polymeric sandwich composite consist of a large array of products because of the ability to modify the base components, the "assembly" techniques.

Polymeric sandwich composite products present a real scientific and technical interest, which justifies the development of research in this field, as well as the increase in the production of such materials.

Because of this, polymeric sandwich composite materials have become indispensable for the development of some top fields like microelectronics, medical equipment and aerospace constructions ( Opran et al., 2009).

Following this trend, there is a need to optimize the way for these polymeric sandwich composites products that are machined, that determine, both in theory and in the laboratory, of a global indicator to define and hold all the factors that may influence the machining process (Tsai S.W., 2008).

\section{METHOD, MEANS AND CONDITIONS FOR THE MILLING WHEN DETERMINING THE FORCES}

The devices used for the research on the methods of determining the milling indicators:

\section{Milling machine used:}

Milling machine FIRST MCV 300

- Power of work: $1.2 \mathrm{KW}$;

- Gamma of rotations: 1-10000 mm/min;

- Maximum speed: 8000 rpm/10000 rpm.

Specifications milling tools:

In order to obtain quality products, the literature recommends for milling of materials polymeric sandwich composite products, the use of specialized tools for these types of structure with fiberglass faces and extruded polystyrene core.

SANDVIK Coromant companies and Iscar Cutting Tools, the world leader in polymeric sandwich composite products for cutting tools, and for processing by the nature of the matrix material, reinforcing material nature and arrangement of fibers in the composite, the tool is presented in fig. 1.

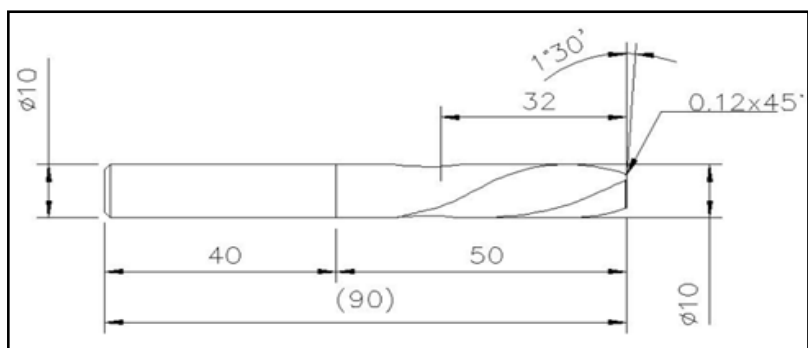

Fig. 1. Milling tool made by SANDVIK Coromat

Material properties are the following:

Materials of which the polymeric sandwich composite products are made of:

$>$ reinforcement element : glass fiber EC12-2400-P207.

$>$ matrix: HELIOPOL 9431 ATYX LSE.

Stand for the study of cutting forces during the milling process for materials made by polymeric sandwich composites products (Fig. 2) is made by: CNC processing center FIRST MCV 300 (1), cell mass Kistler (2), computerized data acquisition systems (3) ( Sanjai K. Mazumdar, 2002)

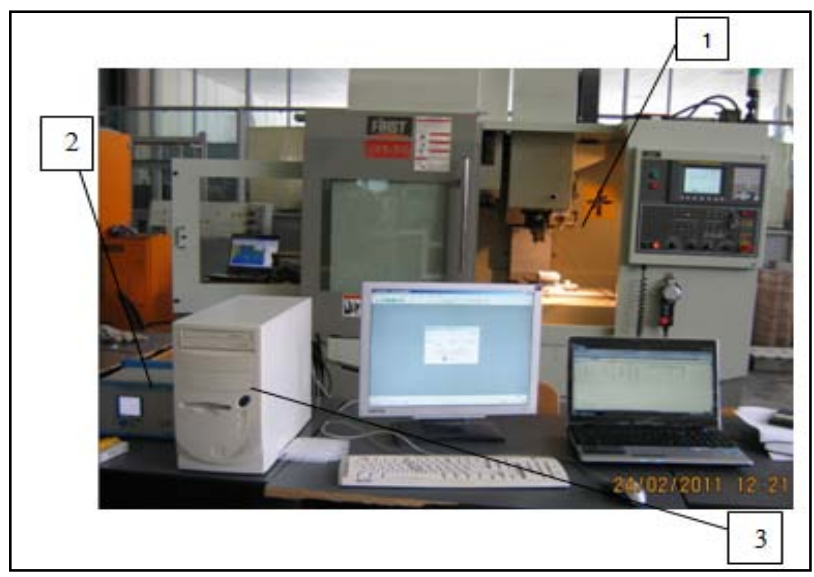

Fig. 2. The registration system

\section{EXPERIMENTAL RESULTS AND DATA PROCESSING}

Technical literature provided equation (1), which has been the starting point in the analysis of cutting forces:

$$
F=C_{F x} \times v_{c}^{x_{F x}} \times f_{z}^{y_{F x}} \times a_{r}^{z_{F x}}[N]
$$

This equation has proved to be inappropriate since after the practical estimation of the polytrophic exponents and constants, several tests determinations has been performed and have 
showed a wide result scattering under the same cutting conditions. The cutting conditions are presented in the table 1 .

\begin{tabular}{|c|c|c|c|}
\hline fz[mm/tooth] & ar[mm] & vc[m/min] & Fx[N] \\
\hline 0.04 & 1 & 219.8 & 55.4 \\
\hline 0.04 & 2 & 62.8 & 42.1 \\
\hline 0.04 & 3 & 219.8 & 50.5 \\
\hline 0.01 & 2 & 219.8 & 52.3 \\
\hline
\end{tabular}

Tab. 1. Cutting conditions

During the machining at various speeds, different parameter values were recorded even if all the other machining conditions are kept constant ( Blajina et al., 2009).

In order to the $C_{F}$ constant and the $x_{F}, y_{F}, z_{F}$, polytrophic exponents were estimated; the equation (2) has been linearized by using the logarithm.

$$
\lg F=\lg C_{F x}+x_{F x} \lg v_{c}+x_{F y} \lg f_{z}+z_{F x} \lg a_{r}
$$

In the data included in Table 1 are substituted in the equation (2), a linear inhomogeneous system of 4 equations with 4 unknowns $\left(x_{F}, y_{F}, z_{F}, \lg C_{F}\right)$ is obtained:

$$
\left\{\begin{array}{l}
\lg C_{F}+x_{F} \lg 219,8+y_{F} \lg 0,04+z_{F} \cdot \lg 1=\lg 55,4 \\
\lg C_{F}+x_{F} \lg 62,8+y_{F} \lg 0,04+z_{F} \cdot \lg 2=\lg 41,1 \\
\lg C_{F}+x_{F} \lg 219.8+y_{F} \lg 0,04+z_{F} \cdot \lg 3=\lg 50,5 \\
\lg C_{F}+x_{F} \lg 219,8+y_{F} \lg 0,01+z_{F} \cdot \lg 2=\lg 52,3
\end{array}\right.
$$

The system has the following solution

$$
C_{F}=22,490 ; x_{F}=0,159 ; y_{F}=-0,011 ; z_{F}=-0,106 \text {. }
$$

The axial cutting force formula for the milling is obtained by inserting this solution in the equation (2):

$$
\mathrm{F}=22,490 \mathrm{v}_{\mathrm{c}}^{0.159} \mathrm{f}_{\mathrm{z}}^{-0.011} \mathrm{a}_{\mathrm{z}}{ }^{-0,106} \quad[\mathrm{~N}]
$$

Experiments 2 and 3 were conducted to test the relation of regression (4). Calculation errors were lower than $2 \%$.

\section{ANALYSIS OF THE RESULTS}

Figures 3, 4, 5 represent the variation of the cutting forces and their dependence to the parameters of the milling polymeric composite material.

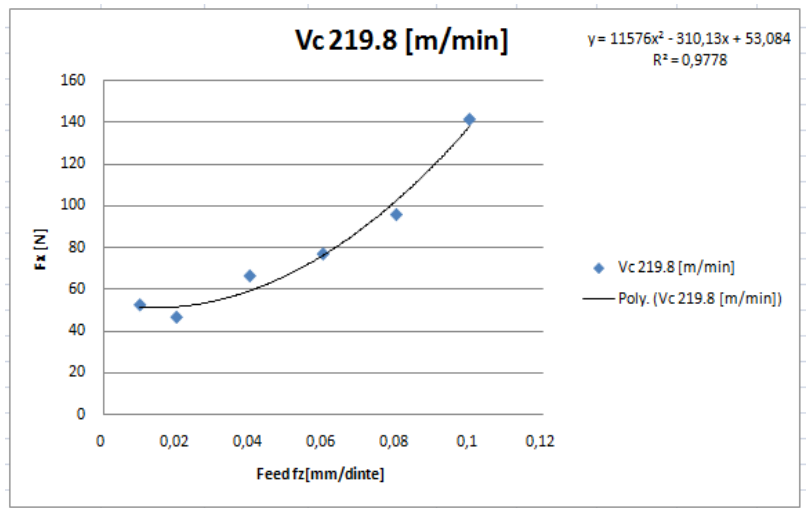

Fig. 3. Shows the variation of axial force as a function of feed rate for $\mathrm{v}_{\mathrm{c}}=\mathrm{ct}$

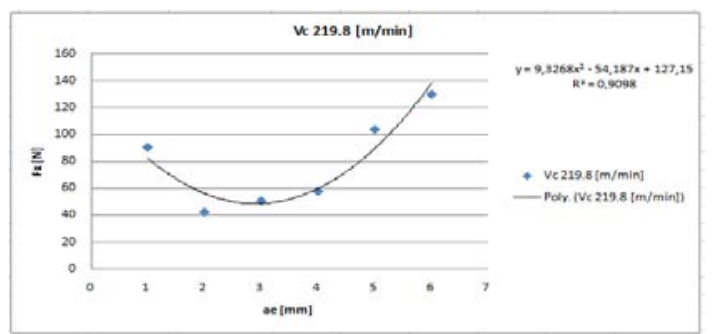

Fig. 4. Shows the variation of axial force as a function of $\mathrm{a}_{\mathrm{e}}$ for $\mathrm{v}_{\mathrm{c}}=\mathrm{Ct}$

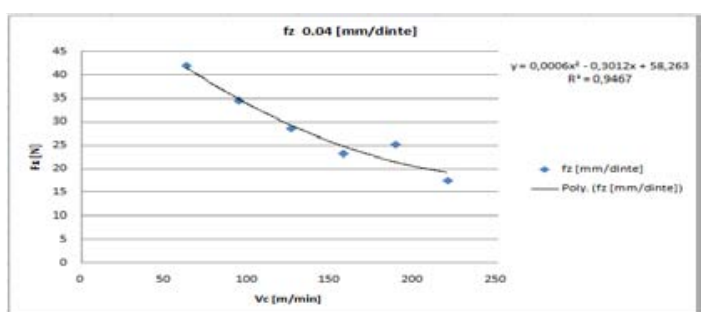

Fig. 5. Shows the variation of axial force as a function of Vc for $\mathrm{f}_{\mathrm{z}}=\mathrm{ct}$

\section{CONCLUSIONS}

The variation of the diagrams shows that the cutting forces for the curved milled increases at an exponential rate if the feed increases and when the mill processing increases, but decrease when the cutting speed decrease. From the analysis of the variation of the cutting forces for this type of polymeric sandwich composite materials, the following conclusions can be drawn: - the diagrams of the forces when milling with a special mill have a good finishing surface, than to mill with a normal tool, not for materials composites.

- from the graphics, one can notice that the variation of the forces is not all the time constant during the milling of the surface; there are some differences between the values recorded at the entry and exit point of the tool.

Next steps are to monitor the milling process for sandwich composites products in interdependence with the forces and torques that will processed a better surface quality.

\section{REFERENCES}

Blajina O., Marinescu A., Opran C., (2009) Modeling the mechanical behaviour of composite sandwich plates, Proceeding of The 6 International Conference on Advanced Manufacturing Technologies, Cluj, Romania, pp. 113-118

Bivolaru C., Opran C., Murar D., (2011) Influence of temperature on polymeric sandwich composite products during milling processing, Proceeding of the International Conference and Exhibition CNC Technologies, bucuresti, Romania, pp. 89-93

Murar D., Opran C., Bivolaru C., (2011) Research regarding mechanical and structural behavior of polimeric biocomposites products, Proceeding of the International Conference and Exhibition CNC Technologies, bucuresti, Romania, pp. 111-114

Opran C.; Blajină O. (2009). Temperature field in EDM of ceramics composites; Annals Of Daaam For 2009\& Proceedings Of The 20th International DAAAM Symposium; Vol. 20, No. 1, pp. 1519-1522, ISSN 17269679, Editor B.Katalinic; Published By DAAAM International; Viena; Austria

Sanjai K. Mazumdar, (2002) Composites ManufacturingMaterials, Product and Process Engineering'”- CRC Prres LLC

Tsai S.W. (2008). Strength \& life of composites, Editor Aeronautics \& Astronautics Stanford University, SUA 